\title{
Biological responses to spider silk-antibiotic fusion protein
}

\author{
Sílvia Gomes ${ }^{1,2,3}$, Jabier Gallego-Llamas ${ }^{3}$, Isabel B. Leonor ${ }^{1,2}$, João F. Mano ${ }^{1,2}$, Rui L. Reis ${ }^{1,2 *}$ and \\ David L. Kaplan ${ }^{3 *}$ \\ ${ }^{1}$ 3Bs Research Group - Biomaterials, Biodegradables and Biomimetics, Department of Polymer Engineering, University of Minho, \\ Headquarters of the European Institute of Excellence on Tissue Engineering and Regenerative Medicine, AvePark, Guimarães, Portugal \\ ${ }^{2}$ Institute for Biotechnology and Bioengineering (IBB), PT Government Associated Laboratory, Braga, Portugal \\ ${ }^{3}$ Departments of Biomedical Engineering, Chemistry and Physics, Tufts University, Medford, MA, USA
}

\begin{abstract}
The development of a new generation of multifunctional biomaterials is a continual goal for the field of materials science. The in vivo functional behaviour of a new fusion protein that combines the mechanical properties of spider silk with the antimicrobial properties of hepcidin was addressed in this study. This new chimeric protein, termed $6 \mathrm{mer}+$ hepcidin, fuses spider dragline consensus sequences (6mer) and the antimicrobial peptide hepcidin, as we have recently described, with retention of bactericidal activity and low cytotoxicity. In the present study, mouse subcutaneous implants were studied to access the in vivo biological response to $6 \mathrm{mer}+$ hepcidin, which were compared with controls of silk alone (6mer), polylactic-glycolic acid (PLGA) films and empty defects. Along with visual observations, flow cytometry and histology analyses were used to determine the number and type of inflammatory cells at the implantation site. The results show a mild to low inflammatory reaction to the implanted materials and no apparent differences between the $6 \mathrm{mer}+$ hepcidin films and the other experimental controls, demonstrating that the new fusion protein has good in vivo biocompatibility, while maintaining antibiotic function.

Copyright $\odot 2011$ John Wiley \& Sons, Ltd.
\end{abstract}

Received 22 March 2011; Accepted 25 April 2011

Keywords spider silk; antimicrobial activity; hepcidin; chimeric protein; tissue engineering; inflammatory response

\section{Introduction}

Over the past few decades, natural polymers have been extensively studied and tailored for potential use in the design of new devices for medical applications, including vascular (Park et al., 2009) and tendon (Pabbruwe et al., 2010) grafts and sealants (Bessa et al., 2010; Janmey et al., 2008). In the case of proteins such as collagen and

\footnotetext{
"Correspondence to: David L. Kaplan, Departments of Biomedical Engineering, Chemistry and Physics, 4 Colby Street, Medford Tufts University, Medford, MA 02155, USA. E-mail: David.Kaplan@tufts.edu or Rui L. Reis, 3B's Research Group-Biomaterials, Biodegradables and Biomimetics, Department of Polymer Engineering, University of Minho, AvePark, Zona Indústrial da Gandra 4806-909 Caldas das Taipas, Guimarães, Portugal.E-mail: rgreis@dep.uminho.pt
}

fibrin, their main sources are animal tissues, viz. skin, tendons (Chung et al., 2007; Hubbell, 2003) and serum (Janmey et al., 2008). However, the use of materials from animal origins has disadvantages, including the risk of disease transmission and immune reactions (Janmey et al., 2008) and batch-to-batch variations (Langer et al., 2004; Romano et al., 2010). Some proteins such as spider silks would be desirable, due to their mechanical properties; however, they are not easy to obtain from nature, unlike the case for gelatin and alginate. In the case of Bombyx mori silkworm silk, sericulture allows for a constant supply of silk from the textile industry that has been extensively utilized in the medical suture field (Omenetto et al., 2010). In the case of spider silk, the supply of natural protein is scarce, since it is difficult to breed spiders (Spiess et al., 2010). In recent years genetically engineered spider silk has been prepared 


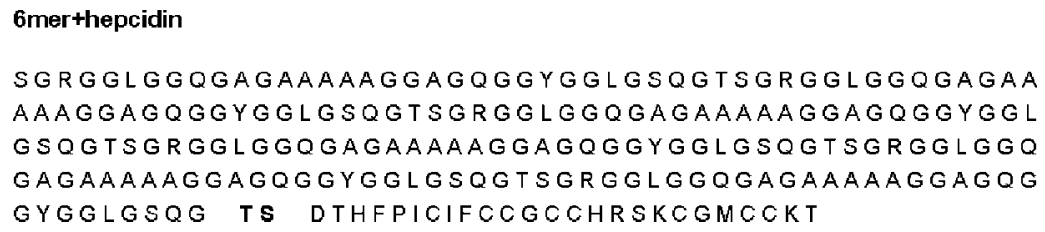

Figure 1. Amino acid sequence for the new chimeric protein, $6 \mathrm{mer}+$ hepcidin. The 6 mer sequence is depicted in black, and grey indicates the hepcidin domain. The TS restriction site was used to insert the hepcidin sequence

and studied for a range of fundamental and applied biomaterials needs (Spiess et al., 2010), including cell culture surfaces (Widhe et al., 2010), nerve regeneration (Allmeling et al., 2006, 2008) and wound dressings (Baoyong et al., 2010). The outstanding mechanical properties of silks (Heim et al., 2010), together with biocompatibility and slow biodegradation in vivo (Xu et al., 1990) and Food and Drug Adminstration (FDA) approval for silkworm silk biomaterials, are driving interest in a broader range of silk-based biomaterials for medical needs (Hardy et al., 2009).

Spider dragline silk is one of the many different types of silk produced by some spiders and the core filament is formed by two spidroin protein molecules, the major ampullate spidroin protein 1 (MaSp1) and protein 2 (MaSp2) (Mahoney et al., 1997). MaSp has two chemically distinct blocks or peptide regions: hydrophilic GGX motifs ( $\mathrm{G}$ stands for glycine and $\mathrm{X}$ is mostly glutamine) and hydrophobic poly-alanine (poly-A) motifs (Hayashi et al., 1999). GGX motifs assume a helical conformation, forming less crystalline and amorphous regions with elastic properties (Beek et al., 2002), which alternate with the poly-A motif crystalline regions, characterized by tightly packed anti-parallel $\beta$-sheets responsible for the stiffness of silk fibres (Sponner et al., 2007). Additionally, MaSp1 protein produced by the spider species Nephila clavipes is one of the most studied silks via recombinant DNA technology (Rabotyagova et al., 2009; Scheibel, 2004; Xiaa et al., 2010). MaSp1 production in heterologous expression systems, such as Escherichia coli, has advantages over natural sources, since these expression systems represent a constant source of spider silk, providing sufficient amounts of protein for study. Further, this genetic-engineering approach provides a path for precise control over the amino acid sequence in the protein, including the chain length and the sequence chemistry. This approach also offers the possibility of enriching the native sequence with other protein motifs with specific bioactivities or functions, thereby generating new chimeric proteins with selective biological activity. Silk-based block copolymers have been fused with different protein motifs, such as RGD, a cellbinding domain known to improve cell adhesion, for the design of tailored silk systems for gene delivery (Numata et al., 2010). Also, dentin matrix protein and bone sialoprotein motifs have also been combined with spider silk block copolymers to improve osseointegration, highlighting the potential of these bioengineered silk protein-based biomaterials for tissue engineering (Gomes et al., 2010; Huang et al., 2007).
In the present study the in vivo biological responses to a new chimeric protein with antimicrobial features, designated 6 mer + hepcidin (Figure 1), were assessed. The 6 mer stands for a spider silk block copolymer formed by six repeats of the MaSp1 consensus sequence. We previously described the design of this fusion protein and activity studies demonstrated that antimicrobial activity of the chimeric protein was preserved when evaluated against E. coli and Staphylococcus aureus. Cell viability and proliferation studies also supported that there were not obvious cytotoxic effects from the chimeric protein on mammalian cells (Gomes et al., 2011). These data set the stage for the current study, where in vivo responses to the protein were addressed to further determine the feasibility of this type of protein for new biomaterial systems.

Hepcidin is a antimicrobial peptide expressed by the liver (Krause et al., 2000) and different studies have demonstrated its antibacterial activity against different stains of Gram-positive $\left(\mathrm{Gram}^{+}\right)$and Gram-negative $\left(\mathrm{Gram}^{-}\right)$bacteria, such as: Gram ${ }^{-}$E. coli ML35 strain and Neisseria cinerea, and $\mathrm{Gram}^{+}$S. aureus, S. epidermis, S. carnosus, Bacillus cereus, B. megaterium, B. subtilis, Micrococcus luteus and group B Streptococcus (Koliaraki et al., 2008; Wallace et al., 2006; Zhang et al., 2005). Besides being an antimicrobial peptide, hepcidin also emerged as an important regulator of iron homeostasis, acting as an iron regulatory hormone and behaving as a negative regulator of intestinal iron absorption, iron transport across the placenta and macrophage iron release (Ganz, 2003). Besides many other functions, iron is an important element in infections and many pathogens have developed the ability to sequester iron from host. Therefore, iron deficiency may limit bacteria growth and inhibit the formation of biofilms (Singh et al., 2002).

The role of hepcidin in iron metabolism was first demonstrated when overexpression of mRNA coding for hepcidin in the liver of iron-overloaded mice was reported (Pigeon et al., 2001). Hepcidin mRNA overexpression by hepatocytes was also observed after treatment of the mice with lipopolyssacharide (LPS) (Ganz, 2003). A 25fold increase in hepcidin mRNA levels were found within $8 \mathrm{~h}$ after treatment with interleukin-6 (IL-6), a cytokine produced by monocytes and macrophages exposed to LPS (Nemeth et al., 2003). These studies showed that hepcidin expression is regulated by iron as well as by immune stimuli. Upon infection, hepcidin acts in a dual way against bacteria, by reducing the amount of iron available for bacteria growth and also by attacking the 
bacteria directly (Falzacappa et al., 2005). Hepcidin's dual antimicrobial role in the infectious process makes it an attractive target in the design of biomaterials for biomedical applications. These biomaterials could be used in the design of a new generation of grafts to reduce infections after surgery and to prevent the formation of bacterial biofilms, a significant cause of implant failure (Rohde et al., 2010; Schierholz et al., 2002). Promising results were obtained in vitro with the 6 mer + hepcidin (Gomes et al., 2011), where the potential of a highly tailored multifunctional protein system for biomaterials was described. The system combined the mechanical features of silk protein and the antimicrobial properties of hepcidin peptide. These in vitro results, together with the role of hepcidin in inflammation, are the starting point for the present in vivo study. Early biological responses to $6 \mathrm{mer}+$ hepcidin films were assessed, along with controls including polylactic-glycolic acid (PLGA) films and silk alone (6mer), as well as empty defects. PLGA is a synthetic polymer approved by the Food and Drug Administration (FDA) for drug delivery and diagnostic and other clinical and basic science applications, such as cardiovascular disease, cancer, vaccines and tissue engineering (Lü et al., 2009). Films were implanted subcutaneously in mice and responses were assessed visually, via histology and with flow cytometry analysis.

\section{Materials and methods}

\subsection{Cloning}

The design and cloning of the 6mer (Bini et al., 2006, Rabotyagova et al., 2009) silk control, and the 6 mer + hepcidin (Gomes et al., 2011) sequences was described in our previous studies. Briefly, a $\mathrm{pET30a}^{+}$(Novagen, San Diego, CA, USA) vector was used for the construction of pET30L carrying the 6mer silk block co-polymer coding sequence with a SpeI restriction site next to it for further sequence insertions. The hepcidin cDNA sequence was prepared by annealing synthetic singlestranded oligonucleotides (Invitrogen, Carlsbad, CA, USA) encoding for hepcidin. The resultant cDNA doublestrand sequence carried SpeI and NheI restriction sites for insertion into the vector pET30L +6 mer. After digestion with SpeI (R0133S, New England Biolabs, Ipswich, MA, USA) and NheI (R0131S, New England Biolabs), the hepcidin cDNA sequence was inserted into pET30L + 6mer vector, using T4 DNA ligase (M0202S, New England Biolabs). The ligation product was transformed into Escherichia coli DH5 $\alpha$ cells (18 258012, Invitrogen). Successful transformants were identified by plating on agar containing $25 \mu \mathrm{g} / \mathrm{ml}$ kanamycin. The presence of the hepcidin insert was confirmed by DNA sequencing (Tufts Core Facility, Boston, MA, USA).

\subsection{Protein expression, purification and characterization}

\subsubsection{Protein expression and purification}

The constructs pET30L +6 mer and pET30L +6 mer + hepcidin were used to transform E. coli RY-3041, a mutant strain of $E$. coli BLR(DE3) defective in the expression of SlyD protein (Huang et al., 2003; Yan et al., 2001). Bacteria were cultivated at $37^{\circ} \mathrm{C}$ in Hyper Broth $^{\mathrm{TM}}$ (0107-S, Athens Enzyme Systems) with $25 \mu \mathrm{g} / \mathrm{ml}$ kanamycin (K1876, Sigma, St. Louis, MO, USA) until $\mathrm{OD}_{600}=0.9-1$. Protein expression was induced with isopropyl $\beta$-D-thiogalactoside (IPTG, 15529019 , Invitrogen) at a concentration of $0.5 \mathrm{mM}$. After $2 \mathrm{~h}$ the cells were harvested by centrifugation at $6500 \mathrm{rpm}$ and the bacterial pellet was lysed in denaturating buffer (100 mM NaH${ }_{2} \mathrm{PO}_{4}, 10 \mathrm{~mm}$ Tris-HCl, $8 \mathrm{M}$ urea, pH 8.0) and left overnight with stirring for complete cell lysis. For removal of cell debris, the mixture was centrifuged at $11000 \mathrm{rpm}$. The resultant protein solution was incubated for $2 \mathrm{~h}$ with Ni-NTA resin (30250, Qiagen, Valencia, CA, USA) with stirring. The protein/Ni-NTA resin mixture was loaded onto a glass Econo-column (Biorad, Hercules, CA, USA). After washing several times with denaturating buffer at $\mathrm{pH} 8$ and $\mathrm{pH}$ 6.0, proteins were eluted with denaturating buffer with $\mathrm{pH}$ 4.5. Eluted protein solutions were dialysed first in a $20 \mathrm{mM}$ sodium acetate buffer, followed by extensive dialysis in Milli-Q (MQ) water, using cellulose ester snake skin membranes with a 100-500 Da molecular weight cut-off (131 054, Spectra/Por Biotech, Rancho Dominguez, CA, USA) for salt removal. Finally, the dialysed proteins were lyophilized.

\subsubsection{SDS-PAGE electrophoresis}

The purity of the 6mer and 6mer + hepcidin proteins was verified by sodium dodecyl sulphate-polyacrylamide gel (SDS-PAGE) electrophoresis, followed by colloidal blue staining. Briefly, proteins were mixed with NuPAGE LDS sample buffer (NP0007, Invitrogen) and heated at $80^{\circ} \mathrm{C}$ for $10 \mathrm{~min}$. The samples were loaded into a bis-tris 4-12\% gel (NP0321BOX, Invitrogen) for electrophoresis separation. Afterwards, the gels were stained with a colloidal blue kit (LC6025, Invitrogen) for protein band detection.

\subsubsection{Amino acid composition analysis}

Amino acid analysis was carried out at Yale University, W. M. Keck Foundation Biotechnology Resource Laboratory (New Haven, CT, USA) on a Hitachi L-8900 amino acid analyser (Tokyo, Japan), following an overnight in vacuo acid hydrolysis at $115^{\circ} \mathrm{C}$. The analyser uses an ionexchange column with a $\mathrm{pH}$ and temperature gradient to separate the amino acids. EZChrome Elite for Hitachi software was used to run the analyser, collect and finally to analyse the data (table S1). 


\subsubsection{MALDI-TOF and protein sequencing}

Matrix-assisted laser desorption-time-of-flight (MALDITOF; Voyager-DE Pro, Applied Biosystems, CA, USA) and protein sequencing (ABI 494, Applied Biosystems, CA, USA) were used to confirm protein identity and both analyses were performed at the Tufts University Core Protein Chemistry Facility (Boston, MA, USA). For MALDI-TOF, samples were dissolved in water at a concentration of $2 \mathrm{mg} / \mathrm{ml}$. Protein sequencing was carried out with samples extracted from the protein bands observed by SDS-PAGE after electrophoresis and colloidal blue staining.

\subsection{Fabrication of protein films}

Protein films were prepared by dissolving the lyophilized 6 mer or 6 mer + hepcidin proteins in MQ water to a final concentration of $2 \% \mathrm{~m} / \mathrm{v}$. Then $60 \mu \mathrm{l}$ each protein solution was cast onto a non-adherent polystyrene surface and left to dry at room temperature. After complete drying, the films were treated with $90 \% \mathrm{v} / \mathrm{v}$ methanol solution for $30 \mathrm{~min}$ to induce $\beta$-sheet conformation, thereby inducing insolubility of the proteins. With methanol treatment there was an improvement in the mechanical properties of the films as well as preventing immediate dissolution in culture media or in vivo in contact with body fluids. After methanol treatment, the films were left to dry for 3 days for methanol evaporation.

PLGA film controls were prepared by dissolving PLGA with a molecular weight in the range $40-75 \mathrm{kDa}$ (P2191, Sigma) in dichloromethane in a 1:15 ratio. After complete dissolution, $60 \mu \mathrm{l}$ PLGA solution was cast onto a polystyrene surface and left to dry at least for 2 days for complete dichloromethane evaporation. PLGA is a synthetic polymer that was selected as a control in the present study as it is biocompatible and biodegradable (Bala et al., 2004) and is approved by the FDA for use in sutures, bone plates and drug delivery systems (Bala et al., 2004; Mishra et al., 2008). For sterilization, the PLGA, 6mer and 6mer + BSP films were treated with $70 \% \mathrm{v} / \mathrm{v}$ ethanol solution for $30 \mathrm{~min}$ and immediately before implantation each film side was treated for $15 \mathrm{~min}$ with ultraviolet (UV) light. Before implantation, the films were hydrated with sterile phosphate-buffered saline (PBS) for $15 \mathrm{~min}$. The films had a final diameter of ca. $8 \mathrm{~mm}$.

\subsection{Grafting}

All procedures were conducted under animal care protocols approved by Tufts Institutional Animal Care and Use Committee. Subcutaneous grafting was performed in the back of balb/c female mice, 5-7 weeks old, purchased from Charles River (Wilmington, MA, USA) breeding laboratories. A total of 40 animals were used in this study. The animals were divided into four groups of five animals, three groups carrying the 6 mer, 6 mer+ hepcidin and PLGA films, respectively, and a fourth control group, formed with animals subjected to the same surgical procedure but carrying no implant.

The animals were anaesthetized with isoflurane and part of the back of each was shaved with an electric razor and disinfected with $70 \% \mathrm{v} / \mathrm{v}$ ethanol solution. Under anaesthesia and after disinfection, a longitudinal dorsal incision, ca. $1 \mathrm{~cm}$ long, was prepared using fine scissors. Grafts were inserted into a subcutaneous pocket between the skin and muscular layers. A single test sample was implanted in each animal. The incisions were closed with polyester/Dacron suture line and the surgical wounds were again disinfected with betadine. The incisions were monitored, as were the animals, for atypical signals. The animals were sacrificed by cervical dislocation after 2 and 6 weeks to retrieve the implanted materials and to check for inflammatory responses. The implants, together with the overlying tissue, were removed and processed for flow cytometry and histology analysis, as described in the following sections.

\subsection{Flow cytometry analysis}

\subsubsection{Cell isolation}

For cell isolation, the tissue surrounding the implant was removed and minced with the help of scissors or a scalpel. The minced tissue was digested in $2 \mathrm{mg} / \mathrm{ml}$ collagenase IV (17104019, Invitrogen) and $1.2 \mathrm{U} / \mathrm{ml}$ dispase (17 105 041, Invitrogen) solution, prepared in PBS, for $2 \mathrm{~h}$ at $37^{\circ} \mathrm{C}$ with occasional stirring. The digestion mixture was centrifuged at $1500 \mathrm{rpm}$ for $5 \mathrm{~min}$ at $4{ }^{\circ} \mathrm{C}$, the supernatant was removed and the pellet was resuspended at ca. $10^{6}$ cells $/ \mathrm{ml}$ in flow cytometry buffer [PBS supplemented with $0.5 \% \mathrm{v} / \mathrm{v}$ bovine serum albumin (BSA)]. To eliminate undigested tissue, the mixture was passed through a $100 \mu \mathrm{m}$ pore cell strainer, collected in a $50 \mathrm{ml}$ Falcon tube and again centrifuged at $1500 \mathrm{rpm}$ for $5 \mathrm{~min}$ at $4{ }^{\circ} \mathrm{C}$. To remove the red blood cells, the cell pellet was resuspended in $5 \mathrm{ml}$ lysis buffered solution (containing $\mathrm{NaCl} 137 \mathrm{mM}, \mathrm{Na}_{2} \mathrm{HPO}_{4}$ $8 \mathrm{mM}, \mathrm{KH}_{2} \mathrm{PO}_{4} 1.46 \mathrm{mM}, \mathrm{KCl} 2.68 \mathrm{~mm}$, in distilled water at $\mathrm{pH}$ 7.0). After 4-5 min incubation, 20-30 $\mathrm{ml}$ PBS was added to stop the reaction. The cell suspension was centrifuged as before, followed by two washes with flow cytometry buffer. Blocking was carried out by suspending the cell pellets in PBS, followed by $15 \mathrm{~min}$ incubation on ice in the presence of rat anti-mouse FcRII/III antibody (clone 2.4G2, 553 141, BD Pharmingen, Franklin Lakes, NJ, USA). The antibody reacts specifically with a common epitope on the extracellular domains of mouse Fc $\gamma$ II/III receptors and blocks non-antigenspecific binding of immunoglobulins to the Fc $\gamma$ II, Fc $\gamma$ III and possibly Fc $\gamma$ I receptors, in vitro and in vivo. After spinning the cell pellet at $1500 \mathrm{rpm}$ for $5 \mathrm{~min}$ at $4{ }^{\circ} \mathrm{C}$, the cells were resuspended in $500 \mu$ l flow cytometry buffer and used for cell immunostaining for flow cytometry analysis. 


\subsubsection{Cell labelling}

For antibody staining, $50 \mu \mathrm{l}$ cell suspension prepared as above was aliquoted and gently mixed with second antibody solution and incubated on ice for around $30 \mathrm{~min}$. Secondary antibodies were labelled with allophycocyanine (APC), phycoerythrin (PE), AlexaFluor ${ }^{\circledR}$ and fluorescein isothiocyanate (FITC) fluorescence dyes. After incubation with secondary antibody, the cells were washed twice with flow cytometry buffer and resuspended in 200-300 $\mu$ l of the same buffer supplemented with ethylenediaminetetra-acetic acid (EDTA; 431 788, Sigma) to protect the cells until flow cytometry analysis. Brief descriptions of the secondary antibodies used in this study to assess biological responses to the implanted materials are given below:

PE-conjugated CD14. (557740, BD Pharmingen, San Jose, CA, USA) antibody reacts with CD14 glycoprotein expressed by cells of monocyte and macrophage lineages and to a lesser extent by granulocytes. CD14 is a receptor for lipopolysaccharide (LPS) complex, a component of the outer membrane of Gram-negative bacteria. After recognition of the LPS complex, cells from the immune system rapidly engage in inflammatory defence mechanisms, which in some cases can lead to septic shock (Schütt, 1999).

AlexaFluor ${ }^{\circledR}$-conjugated CD4. (557 667, BD Pharmingen) antibody recognizes CD4 surface marker, a transmembrane glycoprotein expressed by developing thymocytes, major histocompatibility class II restricted mature T lymphocytes, including T helper cells and immunosuppressive T cells (Bowers et al., 1997), and a subset of natural killer $\mathrm{T}$ cells (Bendelac, 1995). CD4 is critical in both thymocyte development and $\mathrm{T}$ cell activation and the expression of CD4 surface marker by $\mathrm{T}$ cells during development induces its differentiation into $\mathrm{T}$ helper cells exclusively (Bowers et al., 1997).

FITC-conjugated CD3. (555 274, BD Pharmingen) antibody reacts with the CD3 component of $\mathrm{T}$ cell receptor (TCR), a multimeric surface complex resulting from the assembly of seven different proteins. The T cell receptorassociated CD3 complex is expressed on many thymocytes and mature $\mathrm{T}$ lymphocytes and is essential for antigen recognition and the resulting specific immunity (Clevers et al., 1988).

APC-conjugated CD25. (558643, BD Pharmingen) antibody acts against the low-affinity CD25 subunit (IL2 receptor- $\alpha$ ), forming the interleukin-2 receptor (IL$2 \mathrm{R}$ ), a surface cell receptor expressed in activated $\mathrm{T}$ and $B$ lymphocytes. IL-2R recognizes the interleukin-2 molecule which triggers cell proliferation and the emergence of effector $\mathrm{T}$ cells important for the full expression of immune responses (Chao et al., 2002).
AlexaFluor ${ }^{\circledR}$-conjugated CD8a. (557 668, BD Pharmingen) antibody recognizes the $38 \mathrm{kDa} \alpha$ and $34 \mathrm{kDa} \alpha^{\prime}$ chains of the CD8 coreceptor, a $\mathrm{T}$ cell surface glycoprotein expressed by the major histocompatibility class I restricted cytotoxic $\mathrm{T}$ cells and involved in antigen recognition by cytotoxic T lymphocytes. CD8, as CD4 coreceptor, is critical for the development and activation of $\mathrm{T}$ cells (Janeway, 1992).

\subsubsection{Instrumentation}

Analyses were performed in a four-colour FACSCalibur instrument (Becton Dickinson, NJ, USA) equipped with a $488 \mathrm{~nm}$ argon-ion laser and a $635 \mathrm{~nm}$ red diode laser, and data were processed using FlowJo analysis software (Tree Star, OR, USA).

\subsection{Histological procedure}

Samples were retrieved after 2 and 6 weeks of implantation for histological examination. Immediately after collection, the samples were immersed in a $4 \%$ formalin buffer solution and sent for processing and staining at the Tufts University Animal Pathology Core Laboratory. The samples were embedded in paraffin and $10 \mu \mathrm{m}$ sections were prepared. Haematoxylin and eosin (H\&E) staining was used.

\subsection{Statistics}

All statistical analyses were performed using SPSS 17.0 software. The Shapiro-Wilk test was used to assess the normality of the data. To test for significant differences between experimental groups (6mer + hepcidin, 6mer, PLGA and empty controls), one-way ANOVA was used in conjugation with Dunet's T3 post hoc test for multiple comparison. $p<0.05$ was considered statistically significant.

\section{Results}

\subsection{Protein characterization}

SDS-PAGE analysis of the proteins showed an apparent molecular weight around $28 \mathrm{kDa}$ for both the 6 mer, with an expected molecular weight of $21.8 \mathrm{kDa}$, and the 6 mer + hepcidin, with an expected molecular weight of $23 \mathrm{kDa}$ (Figure 2). In the case of the 6 mer + hepcidin, higher molecular weight protein bands were also observed, which correspond to dimers and multimers as previously observed (Zhang et al., 2005). Amino acid analysis confirmed the corrected composition of the chimeric protein ( 6 mer + hepcidin) and the control (6mer). As expected, glycine and alanine were the most abundant amino acids in both 6 mer and 6 mer + hepcidin proteins. MALDI-TOF analysis confirmed protein identity 


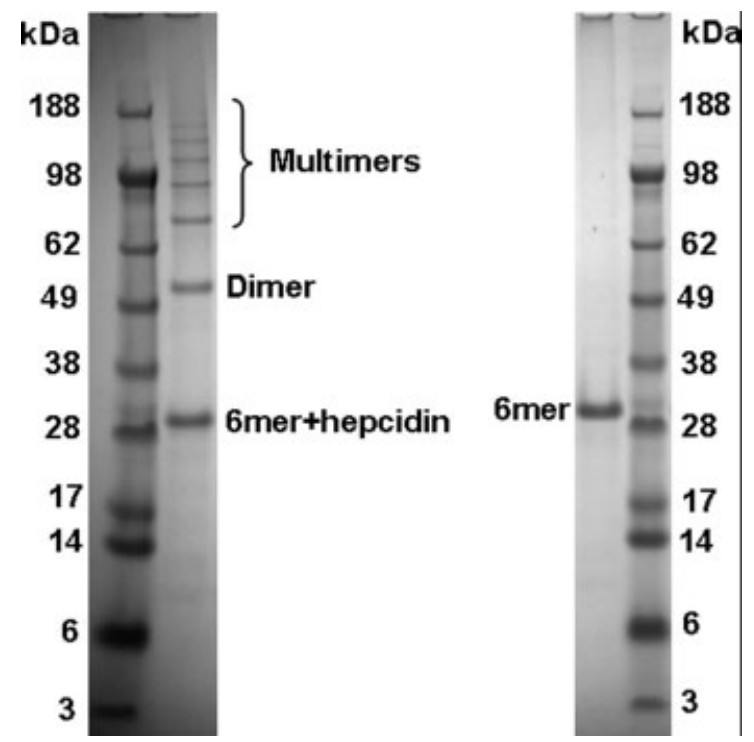

Figure 2. SDS-PAGE gel electrophoresis showing two bands of around $28 \mathrm{kDa}$ for $6 \mathrm{mer}$ and $6 \mathrm{mer}+$ hepcidin. Dimers and multimers were also observed for the 6 mer + hepcidin

and showed a peak at $20.9 \mathrm{kDa}$ for the 6 mer protein, a value close to the expected molecular weight of $21.8 \mathrm{kDa}$. For the 6 mer + hepcidin, MALDI-TOF analysis showed a peak at $22.9 \mathrm{kDa}$, a value very near to $23 \mathrm{k}$ Da predicted size. Finally, protein sequencing analysis confirmed the $N$ terminal sequence for both the 6 mer and 6 mer + hepcidin proteins.

\subsection{Cell characterization by flow cytometry analysis}

All animals survived without visible signs of stress or inflammation. After cell isolations from the implant sites, five different surface markers were assessed for cell types present in the implantation region after 2 and 6 weeks: CD4, CD8, CD14, CD3 and CD25. In Figure 3, representative flow cytometry plots are shown for the labelling, and these data were used to determine the percentage of positive cells expressing the surface marker of interest (Figure 4). Two weeks after grafting the CD3 marker had the lowest expression values in the range $6.8-12.4 \%$ for the empty controls and the 6mer films, respectively. In Figure 4A no major differences betweens the plots for the samples and the empty control were found and statistical comparison showed no significant differences ( $p<0.05$ ) between samples. CD4 showed the highest expression values, with an average of $67.7 \%$, $60.6 \%, 77.7 \%$ and $68.4 \%$ for the $6 \mathrm{mer}$, PLGA, empty control and $6 \mathrm{mer}+$ hepcidin, respectively (Figure 4A). For the CD4 marker, the presence of a second population of positive cells with high fluorescent levels was evident from the flow cytometry plots in the figure. ANOVA analysis for CD4 showed significant differences $(p<0.05)$ between samples and Dunet's T3 post hoc test for multiple comparison showed significant differences between the PLGA and empty controls. For CD25 antigen, ANOVA analysis showed a significant difference between PLGA,
6 mer and 6mer + hepcidin and the controls with no implants.

After 6 weeks of implantation, flow cytometry analysis showed an increase in the percentage of cells expressing surface markers CD14, CD8, CD25 and CD3. For CD4, marker expression increased only for the PLGA samples. Figure 4B shows the presence of a second population of positive cells that was not evident for the samples collected after 2 weeks. Also, flow cytometry labelling (Figure 3) showed an increase in fluorescence intensity for most of the surface markers. As in the case of the samples collected after 2 weeks, after 6 weeks CD3 showed the lowest percentage of positive cells, with $12 \%$, $38.5 \%, 26.6 \%$ and $15.3 \%$ for the 6mer, PLGA, empty control and 6mer + hepcidin, respectively. Again, CD4 antigen showed the highest expression for most samples, with values in the range $51.5-71.7 \%$ for the 6 mer and empty control samples (Figure 4B). Statistical comparison showed no significant differences between the different samples for each marker. However, when comparing expression values obtained for the same samples after 2 and 6 weeks, some significant differences were observed. For CD4, a significant $(p<0.05)$ increase in expression from 2 to 6 weeks for the 6 mer and 6 mer + hepcidin samples was found. A significant increase in expression was also observed for CD25 for the 6mer, PLGA and 6mer + hepcidin samples.

\subsection{Histological characterization}

Histological characterization with H\&E staining was also used to assess biological responses to the 6mer + hepcidin films and to compare this to the various controls (6mer, PLGA and empty implants). After 2 weeks a mild inflammatory reaction was detected around the 6mer, 6mer + hepcidin and PLGA implanted films, with 

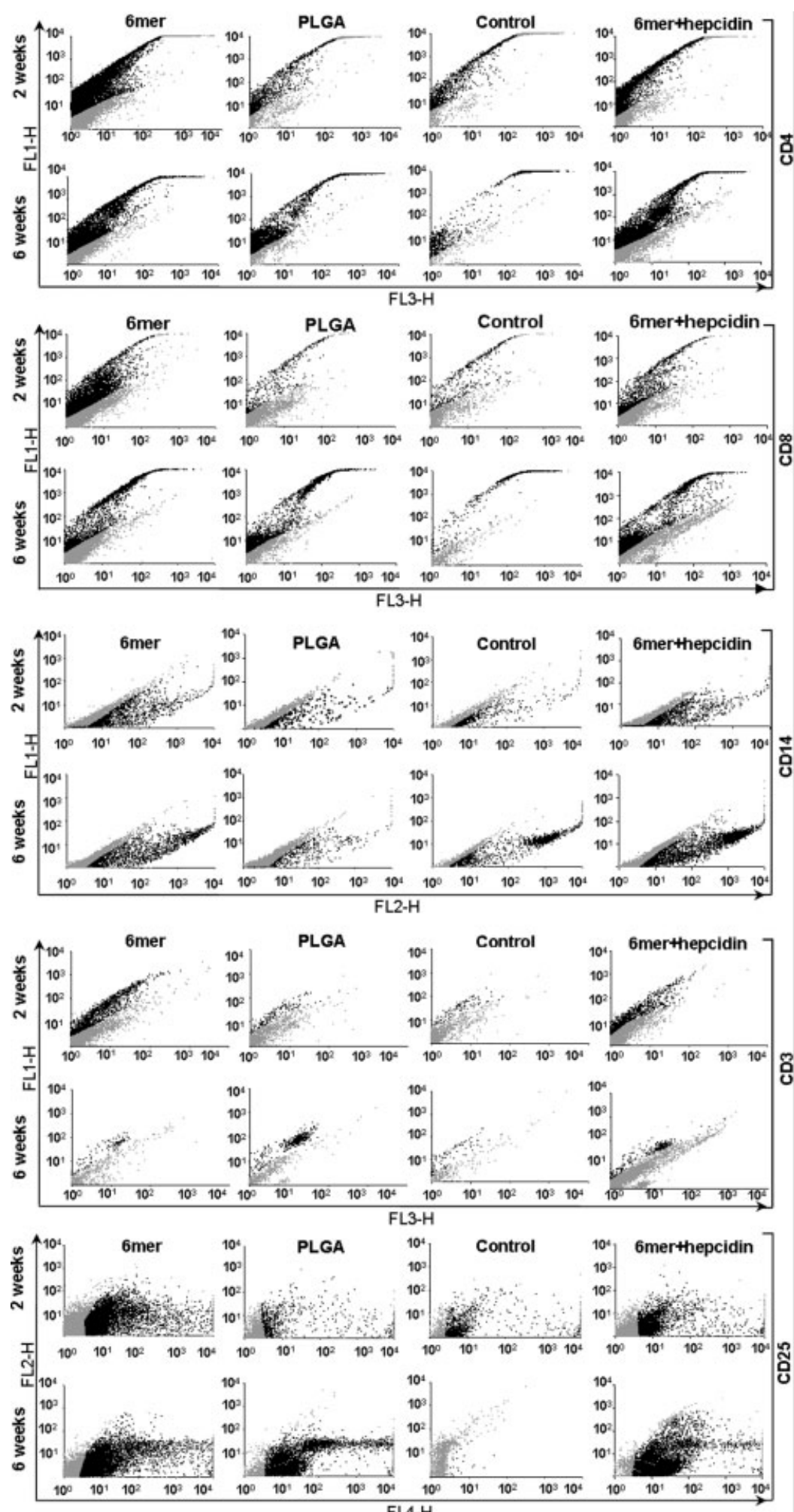

Figure 3. Representative flow cytometry plots for surface markers. Positive cells for the surface markers are depicted in black, and grey indicates the negative cell population 

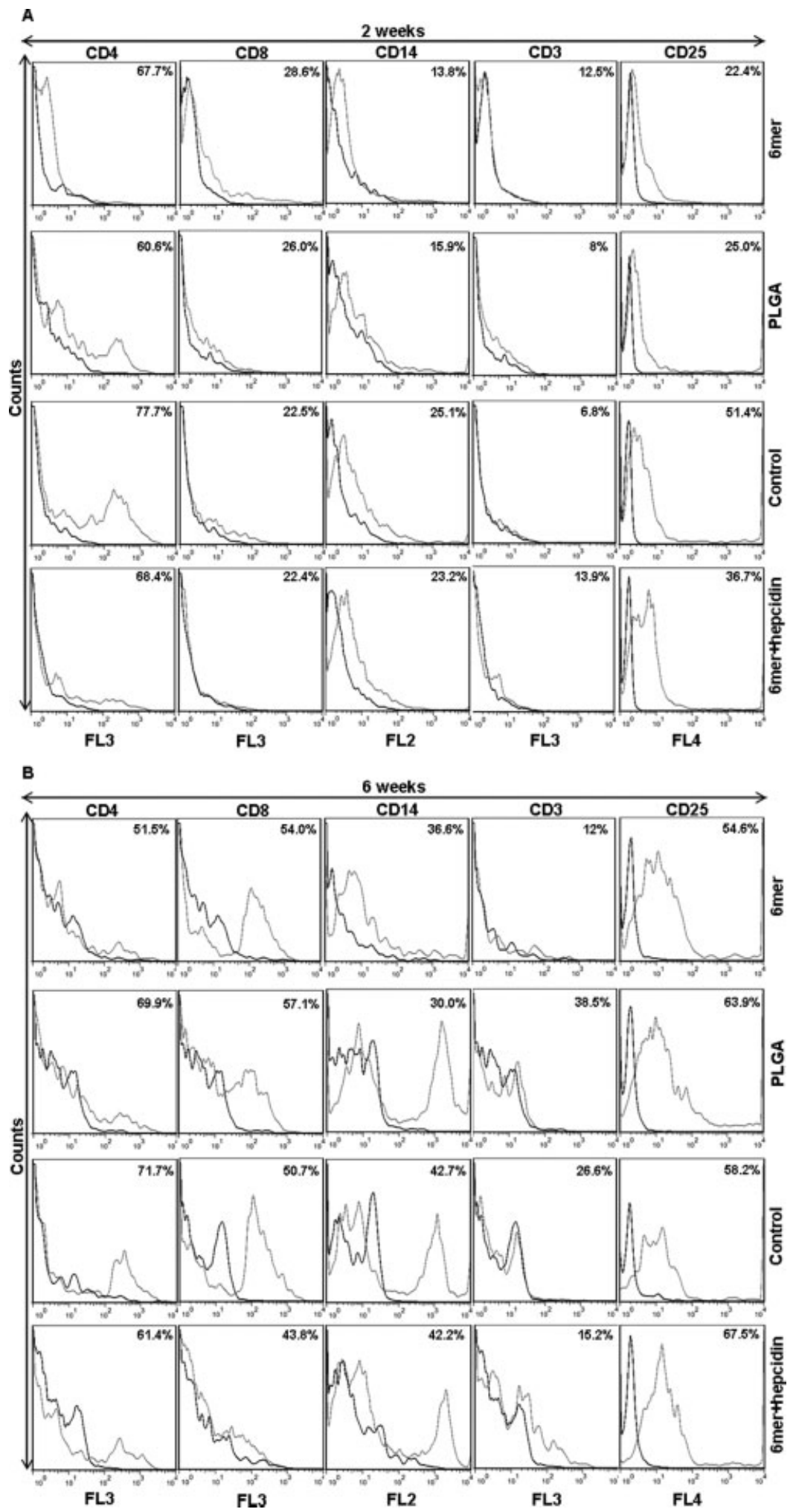

Figure 4. Representative plots of one experiment for the expression of CD4, CD8, CD14, CD3 and CD25 surface markers for the cells extracted from the region surrounding each implant sample at the end of 2 and 6 weeks. Numbers represent the average percentage of positive cells for each marker. Grey indicates marker expression and black indicates the negative control, with no secondary antibody added 


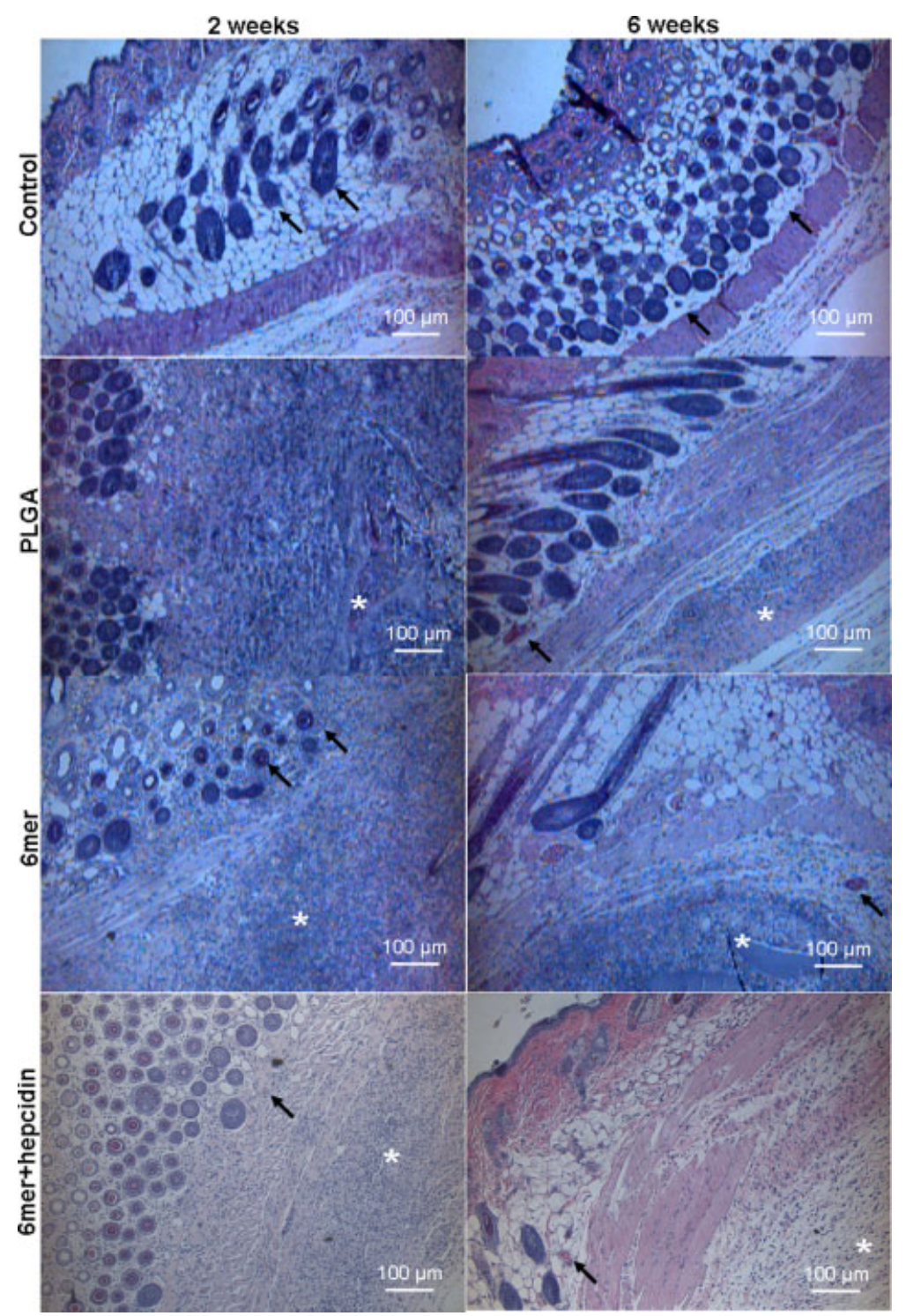

Figure 5. H\&E staining of PLGA, 6mer and $6 \mathrm{mer}+$ hepcidin films and the empty control after 2 and 6 weeks of implantation. Magnification, $\times 10 .^{*}$, implant

fewer cells in the empty controls when compared to the implanted films (Figure 5).

After 6 weeks in vivo, fewer cells could be observed in the tissues surrounding the implants and in the empty controls and a more localized cell response was observed. Moreover, the formation of a fibrous capsule was not detected for any of the implanted materials (Figure 5).

\section{Discussion}

The importance of antimicrobial peptides in the inflammation process has been discussed previously (Hiemstra, 2006; Tecle et al., 2010; Zhang et al., 2005), functioning as chemotactic agent for monocytes and $\mathrm{T}$ cells or involved in activating the acquired immune response system (Grigat et al., 2007). These peptides are also important elements in wound healing (Aarbiou et al., 2004), stimulating the proliferation of fibroblasts and epithelial cells (Aarbiou et al., 2002; Murphy et al., 1993) and inducing neovasculogenesis (Chavakis et al., 2004) and cytokine mobilization (Bals, 2000). In the specific case of hepcidin, besides its direct antimicrobial activity against pathogens, it is also a key element in controlling plasma iron concentration. Due to its role in iron homeostasis, hepcidin is considered to be a crucial link between host defence and iron metabolism (Ganz, 2006). During the early stages of bacterial infections, the exposure of monocytes and macrophages to LPS, a component of the Gram-negative bacterial outer membrane, leads to the secretion of different types of cytokine (Nemeth et al., 2003). The cytokine IL- 6 is secreted by monocytes and macrophages (Amersfoort et al., 2003) and induces hepcidin synthesis by hepatocytes during the acute phase of inflammation in mice and humans (Nemeth et al., 2004). Hepcidin binds to ferroportin an iron transmembrane transporter, which blocks iron efflux from hepatocytes in the liver and macrophages and absorptive enterocytes in 
the small intestine (Vyoral et al., 2005). This binding leads to the degradation of ferroportin, resulting in the trapping of iron inside hepatocytes, macrophages and enterocytes, with a consequent decrease of available serum iron (Vyoral et al., 2005). The decrease in blood iron diminishes the availability of iron for invading microorganisms. As mentioned previously, iron deprivation limits bacterial growth and inhibits biofilm formation, favouring the appearance of mobile individual forms, which are vulnerable to host attack (Ganz, 2003). Therefore, hepcidin has an important role in the early stages of infection and inflammation, exerting dual antimicrobial activity by attacking bacteria directly and by reducing the amount of available iron necessary for microbial metabolism. These characteristics, together with its low cytotoxicity (Park et al., 2001), make hepcidin a promising molecule for use in the design of biomaterials with antimicrobial properties to reduce the risk of infection after implantation.

However, this strong link between hepcidin and the immune system can also elicit an undesired inflammatory response to biomaterials carrying this molecule. For instance, the binding of hepcidin to the ferroportin receptor present in the cell membrane of macrophages (Vyoral et al., 2005) can promote macrophage adhesion to the implant surface, which could accelerate the degradation of the implanted biomaterial and also lead to an intensification of the host immune response. For these reasons, and since the evaluation of tissue-material responses are important in order to assess the suitability of a new biomaterial for biomedical applications, this study addresses the first stages of the inflammatory response to $6 \mathrm{mer}+$ hepcidin films implanted in mice. Flow cytometry analysis was used to access the expression of five different surface markers, CD4, CD8, CD3, CD25 and CD14. These five different markers are specific for different types of immune cells and were used to assess the cellular response to the implanted films. Flow cytometry assay was complemented with histology studies and both analyses showed similar inflammatory responses between the three polymers tested [6mer + hepcidin, PLGA (an FDA-approved polymer) and 6mer] and the empty controls.

Flow cytometry analysis provided a quantitative evaluation of the inflammatory response through different cell markers. CD4 marker had the highest expression levels at both 2 and 6 weeks. As mentioned previously, this marker is expressed by subgroups of $\mathrm{T}$ lymphocytes, such as mature $\mathrm{T}$ helper and immunosuppressive $\mathrm{T}$ cells, and also by natural killer cells. T helper cells activate and direct other immune cells, such as cytotoxic T cells, and maximize the bactericidal activity of macrophages (Zhu et al., 2010). Furthermore, the presence of positive cells for CD8, CD3, CD25 and CD14 was also observed, mainly after 6 weeks, when these markers had stronger expression. Activated CD8 positive cytotoxic T cells are efficient and rapid killers of target cells (Jenkins et al., 2010). These cells only become fully activated in the presence of CD4 T cells and they exert their effect either by releasing lytic granules, which carry molecules capable of forming pores in the membrane of target cells, or by inducing cell apoptosis (Ruiz et al., 2007). The detection of a CD25-positive cell population showed the presence of $\mathrm{B}$ and $\mathrm{T}$ lymphocytes, which are cells responsible for the production of antibodies and for cell-mediated immune responses, respectively (LeBien et al., 2008). Additionally, CD14-positive cells were detected by flow cytometry, which indicates monocytes, macrophages and granulocytes. Macrophage and granulocytes play a role in host inflammatory responses, forming the first line of immune defence (Alba-Loureiro et al., 2007; Haskó et al., 2007).

In conclusion, the flow cytometry results are in concordance with the histology observations and both analyses showed a mild or low inflammatory host response to all of the implanted materials. Flow cytometry indicated the presence of different types of immune cells at the implant site and histological analysis showed these types of cells around the implant. Additionally, except for CD4 in the PLGA films and empty controls, flow cytometry analysis shows no significant differences in either the number or type of inflammatory cells for the $6 \mathrm{mer}+$ hepcidin films when compared with the 6mer, PLGA and empty controls. Since similar responses were observed for the implanted films and for the controls, we conclude that the observed mild or low inflammatory response was not caused by the implanted films. Also, these results show that the host immune response is mild or low and restricted to a local reaction, mainly after 6 weeks.

The in vivo behaviour of different silk implants has been described. The inflammatory response induced after intramuscular implantation of silk and silk-RGD films in mice in comparison to polylactic acid (PLA) and collagen films has been reported (Meinel et al., 2005). The inflammatory response to the silk and silk-RGD films was equivalent to, or less than, that observed for collagen controls, and far less than to PLA film controls. Minimal inflammation responses were observed for silk, silk-RGD and collagen films after 6 weeks (Meinel et al., 2005). For PLA films, the presence of granulomatous inflammation was found based on the presence of multinucleated giant cells and macrophages (Meinel et al., 2005). Degradation of silk films was not observed over the 6 week period, while for collagen there was considerable degradation and only remnants of these films detected (Meinel et al., 2005). Recently, recombinant spider silk films as a wound dressing biomaterial was evaluated in rats (Baoyong et al., 2010). In vivo results showed that, as a biomaterial, the recombinant spider silk films had good biocompatibility and were able to induce skin regeneration. For the silk films, the wound-healing extent was $95-90 \%$ after 21 days (Baoyong et al., 2010). Other studies also addressed the in vivo behaviour of silk-based scaffolds functionalized with bioactive molecules, such as bone morphogenetic protein 2 (BMP-2) (Kirker-Head et al., 2007) and tissue growth factor (TGF- $\beta$ ) (Tang et al., 2009). Although a considerable number of studies addressed the in vitro and in vivo responses to silk-based materials, to our knowledge these are the first results 
reporting the in vivo inflammatory response to a protein graft, fabricated from a chimeric protein combining spider silk with an antimicrobial peptide.

In the literature, the use of biomaterials incorporating antimicrobial peptides is scarce. Recently, Bombyx mori silk fibroin films were modified with a cecropin B antimicrobial peptide, through the carbodi-imide chemistry, showing satisfactory antimicrobial in vitro results (Bai et al., 2008). Furthermore, crosslinked gelatin hydrogels for the delivery of lysozyme antimicrobial peptide prevented the adherence of bacteria to valves used in cardiac valve replacement (Kuijpers et al., 2000). Crosslinked gelatin showed sustained release of lysozyme during $30 \mathrm{~h}$ after implantation, while the lysozyme content in the surrounding tissue was elevated for $50 \mathrm{~h}$. Later a chemically crosslinked gelatin-chondroitin sulphate hydrogel impregnated into Dacron grafts was used as a controlled release system for the delivery of two antimicrobial peptides, lysozyme and recombinant thrombocidin, a protein derived from human blood platelets (Kuijpers et al., 2000). The results showed that crosslinked gelatin-chondroitin sulphate hydrogels had a higher loading capacity for lysozyme and recombinant thrombocidin than crosslinked gelatin hydrogels. Also, in vivo assessments found that the hydrogels were biocompatible and degraded almost completely after 18 weeks of implantation (Kuijpers et al., 2000).

Other studies have described the use of silk and other natural origin-based scaffolds as delivery systems for antibiotic molecules (Bai et al., 2008; Kilian et al., 2008). However, in most cases the scaffolds are soaked in the antibiotic solution and therefore uncontrolled desorption of the immobilized species was observed (Beutner et al., 2010).

Microbial infections are major concerns to the medical community in cases of internal prostheses, cutaneous dressings and other medical devices, such as contact lenses and catheters. To prevent these problems, antibiotic pre-operative prophylaxis and antibiotic local delivery are used. However, even with the extensive use of antibiotics, the frequency of implant-related infections continues to be a major health care concern. Currently used methods of pre-operative prophylaxis and antibiotic local delivery have the major disadvantages of not assuring homogeneous delivery of the drug throughout the host body and of favouring the appearance of antibiotic-resistant strains (Campoccia et al., 2010). Also, the generalized use of antibiotics can lead to the development of resistant bacterial strains. Therefore, there remains an urgent need to develop new biocompatible biomaterials with antimicrobial properties, both to reduce the use of antibiotic drugs and to maintain localized release at the defect site, both issues that can be addressed with the functionalized antimicrobial biomaterial system addressed in the present study.

\section{Conclusions}

In the present study, the biological responses to a new chimeric protein, $6 \mathrm{mer}+$ hepcidin, with antimicrobial activity (Gomes et al., 2011), were reported. Flow cytometry and histology results showed no significant differences in the inflammatory responses between mice carrying the $6 \mathrm{mer}+$ hepcidin films and mice implanted with various controls - PLGA, 6mer or empty defects. These results are promising and give further support to the developing new bioengineered biomaterials with antimicrobial properties that offer a path forward in reduction in the use of antibiotics to prevent infection in implants. The 6mer + hepcidin and other future fusion proteins with antimicrobial properties may represent a new and promising approach to the design of a new generation of multifunctional biomaterials bioengineered to prevent the onset of infections, to be biocompatible and to elicit tissue integration during the tissue regeneration process.

\section{Acknowledgements}

The authors thank Dr Tírcia Santos for her advice on this paper. Sílvia Gomes thanks the Portuguese Foundation for Science and Technology (FCT) for providing a $\mathrm{PhD}$ grant (No. SFRH/BD/28603/2006). This work was carried out under the scope of: the European NoE EXPERTISSUES project (No. NMP3CT-2004-500283); the FIND \& BIND project, funded by the agency EU-EC (FP7 programme); the FCT R\&D project ProteoLight (No. PTDC/FIS/68517/2006), funded by the FCT agency; the Chimera project (No. PTDC/EBB-EBI/109093/2008), funded by the FCT agency; the NIH (Grant No. P41 EB002520) Tissue Engineering Resource Center; and the NIH (Grant Nos EB003210 and DE017207).

\section{Supporting information on the internet}

The following supporting information may be found in the online version of this article:

Table S1. Amino acid composition analysis of 6 mer and $6 \mathrm{mer}+$ hepcidin recombinant proteins

\section{References}

Aarbiou J, Ertmann M, Wetering S, et al. 2002; Human neutrophil defensins induce lung epithelial cell proliferation in vitro. $J$ Leukoc Biol 72: 167-174.

Aarbiou J, Verhoosel RM, Wetering Sv, et al. 2004; Neutrophil defensins enhance lung epithelial wound closure and mucin gene expression in vitro. Am $J$ Respir Cell Mol Biol 30: 193-201.

Alba-Loureiro TC, Munhoz CD, Martins JO, et al. 2007; Neutrophil function and metabolism in individuals with diabetes mellitus. Braz $J$ Med Biol Res 40: 1037-1044.

Allmeling C, Jokuszies A, Reimers K, et al. 2008; Spider silk fibres in artificial nerve constructs promote peripheral nerve regeneration. Cell Prolif 41: 408-420. 
Allmeling C, Jokuszies A, Reimers K, et al. 2006; Use of spider silk fibres as an innovative material in a biocompatible artificial nerve conduit. $J$ Cell Mol Med 10: $770-777$.

Amersfoort ESV, Berkel TJCV, Kuiper J. 2003; Receptors, mediators, and mechanisms involved in bacterial sepsis and septic shock. Clin Microbiol Rev 16: 379-414.

Bai L, Zhu L, Min S, et al. 2008; Surface modification and properties of Bombyx mori silk fibroin films by antimicrobial peptide. Appl Surf Sci 254: 2988-2995.

Bala I, Hariharan S, Kumar MN. 2004; PLGA nanoparticles in drug delivery: the state of the art. Crit Rev Ther Drug Carrier Syst 21: 387-422.

Bals R. 2000; Epithelial antimicrobial peptides in host defense against infection. Respir Res 1: 141-150.

Baoyong L, Jian Z, Denglong C, et al. 2010; Evaluation of a new type of wound dressing made from recombinant spider silk protein using rat models. Burns 36: 891-896.

Beek JD, Hess S, Vollrath F, et al. 2002; The molecular structure of spider dragline silk: folding and orientation of the protein backbone. Proc Natl Acad Sci USA 99: 10266-10271.

Bendelac A. 1995; Mouse NK1+ ${ }^{+}$T cells Curr Opin Immunol 7: 367-374.

Bessa PC, Balmayor ER, Azevedo HS, et al. 2010; Silk fibroin microparticles as carriers for delivery of human recombinant BMPs. Physical characterization and drug release. J Tissue Eng Regen Med 4: 349-345.

Beutner R, Michael J, Schwenzer B, et al. 2010; Biological nano-functionalization of titanium-based biomaterial surfaces: a flexible toolbox. $J$ Roy Soc Interface 7: S93-105.

Bini E, Foo CWP, Huang J, et al. 2006 RGD-functionalized bioengineered spider dragline silk biomaterial. Biomacromolecules 7: 3139-3145.

Bowers K, Pitcher C, Marsh M. 1997; CD4: a co-receptor in the immune response and HIV infection. Int J Biochem Cell Biol 29: 871-875.

Campoccia D, Montanaro L, Speziale P, et al. 2010; Antibiotic-loaded biomaterials and the risks for the spread of antibiotic resistance following their prophylactic and therapeutic clinical use. Biomaterials 31: 6363-6377.

Chao K-H, Wu M-Y, Yang J-H, et al. 2002; Expression of the interleukin-2 receptor- $\alpha$ (CD25) is selectively decreased on decidual $\mathrm{CD}^{+}$and $\mathrm{CD}^{+} \mathrm{T}$ lymphocytes in normal pregnancies. Mol Hum Reprod 8: 667-673.

Chavakis T, Cines DB, Rhee J-S, et al. 2004; Regulation of neovascularization by human neutrophil peptides ( $\alpha$-defensins): a link between inflammation and angiogenesis. FASEB J 18: 1306-1308.

Chung HJ, Park TG. 2007; Surface engineered and drug releasing pre-fabricated scaffolds for tissue engineering. Adv Drug Deliv Rev 59: 249-262.

Clevers H, Alarcon B, Wileman T, et al. 1988; The T cell receptor/CD3 complex: a dynamic protein ensemble. Annu Rev Immunol 6: 629-662.

Falzacappa MVV, Muckenthaler MU. 2005; Hepcidin: iron-hormone and antimicrobial peptide. Gene 364: 37-44.

Ganz T. 2003; Hepcidin, a key regulator of iron metabolism and mediator of anemia of inflammation. Blood 102: 783-788.

Ganz T. 2006; Hepcidin and its role in regulating systemic iron metabolism. Hematol Am Soc Hematol Educ Program 507: 29-35.

Gomes S, Leonor IB, Mano JF, et al. 2010; Spider silk-bone sialoprotein as a novel fusion protein for bone tissue engineering. Soft Matter 7: 4964-4973.

Gomes S, Leonor IB, Mano JF, et al. 2011; Antimicrobial functionalized genetically engineered spider silk. Biomaterials 32(18): 4255-4266.

Grigat J, Soruri A, Forssmann U, et al. 2007; Chemoattraction of macrophages, $\mathrm{T}$ lymphocytes, and mast cells is evolutionarily conserved within the human $\alpha$-defensin family. J Immunol 179: 3958-3965.

Hardy JG, Scheibel TR. 2009; Silk-inspired polymers and proteins. Biochem Soc Trans 37: 677-681.

Haskó G, Pacher P, Deitch EA, et al. 2007; Shaping of monocyte and macrophage function by adenosine receptors. Pharmacol Ther 113: 264-275.

Hayashi CY, Shipley NH, Lewis RV. 1999; Hypotheses that correlate the sequence, structure, and mechanical properties of spider silk proteins. Int $J$ Biol Macromol 24: 271-275.

Heim M, Römer L, Scheibel T. 2010; Hierarchical structures made of proteins. The complex architecture of spider webs and their constituent silk proteins. Chem Soc Rev 39: 156-164.

Hiemstra PS. 2006; Defensins and cathelicidins in inflammatory lung disease: beyond antimicrobial activity. Biochem Soc Trans 34: 276-278.

Huang J, Valluzzi R, Bini E, et al. 2003; Cloning, expression, and assembly of sericin-like protein. $J$ Biol Chem 278: 46117-46123

Huang J, Wong C, George A, et al. 2007; The effect of genetically engineered spider silk-dentin matrix protein 1 chimeric protein on hydroxyapatite nucleation. Biomaterials 28: 2358-2367.

Hubbell JA. 2003; Materials as morphogenetic guides in tissue engineering. Curr Opin Biotechnol 14: 551-558.

Janeway CA. 1992; The $\mathrm{T}$ cell receptor as a multicomponent signalling machine: CD4/CD8 coreceptors and CD45 in T cell activation. Annu Rev Immunol 10: 645-674.

Janmey PA, Winer JP, Weisel JW. 2008; Fibrin gels and their clinical and bioengineering applications. $J$ R Soc Interface 6: $1-10$.
Jenkins MR, Griffiths GM. 2010; The synapse and cytolytic machinery of cytotoxic $\mathrm{T}$ cells. Curr Opin Immunol 22: 308-313.

Kilian O, Hossain H, Flesch I, et al. 2008; Elution kinetics, antimicrobial efficacy, and degradation and microvasculature of a new gentamicin-loaded collagen fleece. $J$ Biomed Mater Res B Appl Biomater 90B: 210-222.

Kirker-Head C, Karageorgiou, Hofmann S, et al. 2007; BMP-silk composite matrices heal critically sized femoral defects. Bone 41: 247-255.

Koliaraki V, Marinou M, Samiotaki M, et al. 2008; Iron regulatory and bactericidal properties of human recombinant hepcidin expressed in Pichia pastori. Biochimie 90: 726-735.

Krause A, Neitz S, Mägert H, et al. 2000; LEAP-1, a novel highly disulfide-bonded human peptide, exhibits antimicrobial activity. FEBS Lett 480: 147-150.

Kuijpers AJ, Wachem PBv, Luyn MJAv, et al. 2000; In vitro and in vivo evaluation of gelatin-chondroitin sulphate hydrogels for controlled release of antibacterial proteins. Biomaterials 21: 1763-1772.

Kuijpers AJ, Wachem PBv, Luyn MJAv, et al. 2000; In vivo and in vitro release of lysozyme from cross-linked gelatin hydrogels: a model system for the delivery of antibacterial proteins from prosthetic heart valves. $J$ Control Release 67: 323-336.

Langer R, Tirrell DA. 2004; Designing materials for biology and medicine. Nature 428: 487-492.

LeBien TW, Tedder TF. 2008; B lymphocytes: how they develop and function. Blood 112: 1570-1580.

Lü J-M, Wang X, Marin-Muller C, et al. 2009; Current advances in research and clinical applications of PLGA-based nanotechnology. Expert Rev Mol Diagn 9: 325-341.

Mahoney DV, Vezie DL, Eby RK, et al. 1997; Aspects of the morphology of dragline silk of Nephila clavipes. In Silk Polymers, Kaplan D, Adams WW, Farmer B, Viney C (eds). American Chemical Society: Charlottesville, VA, USA; 196-210.

Meinel L, Hofmann S, Karageorgiou V, et al. 2005; The inflammatory responses to silk films in vitro and in vivo. Biomaterials 26: 147-155.

Mishra N, Goyal AK, Khatri K, et al. 2008; Biodegradable polymer based particulate carrier(s) for the delivery of proteins and peptides. Curr Med Chem Anti-inflamm Anti Allergy Agents 7: 240-251.

Murphy CJ, Foster BA, Mannis MJ, et al. 1993; Defensins are mitogenic for epithelial cells and fibroblasts. J Cell Physiol 155: 408-413.

Nemeth E, Rivera S, Gabayan V, et al. 2004; IL-6 mediates hypoferremia of inflammation by inducing the synthesis of the iron regulatory hormone hepcidin. J Clin Invest 113: 1271-1276. 
Nemeth E, Valore EV, Territo M, et al. 2003; Hepcidin, a putative mediator of anemia of inflammation, is a type II acute-phase protein. Blood 101: 2461-2463.

Numata K, Hamasaki J, Subramanian B, et al. 2010; Gene delivery mediated by recombinant silk proteins containing cationic and cell binding motifs. $J$ Control Release 146: 136-143.

Omenetto FG, Kaplan DL. 2010; New oppor tunities for an ancient material. Science 329: 528-531.

Pabbruwe MB, Kafienah W, Tarlton JF, et al. 2010; Repair of meniscal cartilage white zone tears using a stem cell/collagen scaffold implant. Biomaterials 31: 2583-2591.

Park CH, Valore EV, Waring AJ, et al. 2001; Hepcidin, a urinary antimicrobial peptide synthesized in the liver. $J$ Biol Chem 276: 7806-7810.

Park IS, Kim SH, Kim YH, et al. 2009; A collagen/smooth muscle cell-incorporated elastic scaffold for tissue-engineered vascular grafts. J Biomater Sci Polym Ed 20: 1645-1660.

Pigeon C, Ilyin G, Courselaud B, et al. 2001; A new mouse liver-specific gene, encoding a protein homologous to human antimicrobial peptide hepcidin, is overexpressed during iron overload. $J$ Biol Chem 16: 7811-7819.

Rabotyagova O, Cebe P, Kaplan DL. 2009; Self-assembly of genetically engineered spider silk block copolymers. Biomacromolecules 10: 229-236.

Rohde H, Frankenberger S, Zähringer U, et al. 2010; Structure, function and contribution of polysaccharide intercellular adhesin (PIA) to Staphylococcus epidermidis biofilm formation and pathogenesis of biomaterial-associated infections. Eur $J$ Cell Biol 89: 103-111.

Romano NH, Sengupta D, Chung C, et al. 2010; Protein-engineered biomaterials: nanoscale mimics of the extracellular matrix. Biochim Biophys Acta 1810 339-349.

Ruiz JH, Becker I. 2007; CD8 cytotoxic T cells in cutaneous leishmaniasis. Parasite Immunol 29: 671-678.

Scheibel T. 2004; Spider silks: recombinant synthesis, assembly, spinning, and engineering of synthetic proteins. Microb Cell Fact 3: 14-24.

Schierholz JM, Beuth J. 2002; Implant infections: a haven for opportunistic bacteria $J$ Hosp Infect 49: 87-93.

Schütt C. 1999; CD14. Int J Biochem Cell Bio 31: 545-549.

Singh PK, Parsek MR, Greenberg EP, et al. 2002; A component of innate immunity prevents bacterial biofilm development. Nature 417: 552-555.

Spiess K, Lammel A, Scheibel T. 2010; Recombinant spider silk proteins for applications in biomaterial. Macromol Biosci 10: 998-1007.

Sponner A, Vater W, Monajembashi S, et al. 2007; Composition and hierarchical organisation of a spider silk. PLOS ONE 2: e998.

Tang QO, Shakib K, Heliotis M, et al. 2009; TGF- $\beta 3$ : a potential biological therapy for enhancing chondrogenesis. Expert Opin Biol Ther 9: 689-701.

Tecle T, Tripathi S, Hartshorn KL. 2010; Review: defensins and cathelicidins in lung immunity. Innate Immun 16: 151-159.

Vyoral D, Petrák J. 2005; Hepcidin: a direct link between iron metabolism and immunity. Int $J$ Biochem Cell Biol 37: 1768-1773.

Wallace DF, Jones MD, Pedersen P, et al. 2006; Purification and partial characterisation of recombinant human hepcidin. Biochimie 88: 31-37.

Widhe M, Bysell H, Nystedt S, et al. 2010; Recombinant spider silk as matrices for cell culture. Biomaterials 31(6): 9575-9585.

Xiaa X-X, Qiana Z-G, Ki CS, et al. 2010; Native-sized recombinant spider silk protein produced in metabolically engineered Escherichia coli results in a strong fiber. Proc Natl Acad Sci USA 107: 14059-14063.

Xu M, Lewis RV. 1990; Structure of a protein superfiber: spider dragline silk. Proc Nat Acad Sci USA 87: 7120-7124.

Yan S-Z, Beeler JA, Chen Y, et al. 2001; The regulation of type 7 adenylyl cyclase by its C1b region and Escherichia coli peptidylprolyl isomerase, SlyD. J Biol Chem 276: 8500-8506.

Zhang H, Yuan Q, Zhu Y, et al. 2005; Expression and preparation of recombinant hepcidin in Escherichia coli. Protein Expr Purif 41: 409-416.

Zhu J, Paul WE. 2010; Heterogeneity and plasticity of $\mathrm{T}$ helper cells. Cell Res 20: 4-12. 